\title{
Measurement of Knowledge and Performance of Pediatric ICU Nurses about Endotracheal Suctioning
}

\author{
Huma Bano, Muhammad Hussain, Muhammad Afzal, Syed Amir Gilani \\ Lahore School of Nursing, The University of Lahore, Punjab, Pakistan
}

\begin{abstract}
Introduction: Safe and aseptic endotracheal suctioning has been a major health challenge in ICU setting, Endotracheal suction is a procedure to insert a suction catheter into the endotracheal tube to remove the secretion. Where endotracheal tube suctioning is essential for a patient with mechanical ventilation to keep their airway clean and infection free, it has also been associated with some adverse effect like hypoxia and ventilator associated pneumonia.in this regard ICU nurses knowledge and competences should be according to set criteria of ETT suctioning procedure. Methods: Target population of this study was ICU nurses of one of the children hospital, Lahore. Sample size was 98.Results: The findings of this research was beyond our expectation as nurses practices was good and their knowledge was fair. Conclusions: This study gives an overview of the ICU nurses knowledge and performance related to ETT suctioning and demonstrates that intensive care nurses' performance regarding endotracheal suctioning is good enough despite fair knowledge. With concerning to these finding there is a need for educational courses, especially theoretical education and motivational session to follow the standard protocol for ETT suction.
\end{abstract}

Keywords: Pediatric, ICU, Knowledge, Performance

DOI: $10.7176 / \mathrm{JHMN} / 73-09$

Publication date: April $30^{\text {th }} 2020$

\section{Introduction}

Endotracheal suction is a procedure to insert a suction catheter into the endotracheal tube to remove the secretion. Endotracheal tube suctioning is essential for a patient with mechanical ventilation, because the mechanics of the breathing and the mucosal ciliary function change, most patients cannot discharge their secretions, so they need indirect suction to clean their airways. Keep free from infection. ETT suctioning is a critical process of maintaining airway patency, it has been associated with various adverse effects as well. Hypoxia, tissue trauma, so it is very important to ensure nurses' abilities on the ETT suction technique through a pre-defined set of criteria. Knowledge, skills and judgment are key factors in defining clinical competence (Davis, Balsara, Remlet, \& Monterisso, 2017).

A descriptive cross sectional study conducted in one of the hospital in Tanzania ( $n=103$ ), to assess the intensive care nurses knowledge and practice regarding ETT suction, The results of the study showed that $70 \%$ of the nurses knew about the procedure indication, however, $80 \%$ demonstrated undesirable overall skills on ETS evidence-based recommendations. Technical discrepancies were observed in practices prior and post ETS events. All nurses observed did not auscultate chest 35(100\%), did not pre-oxygenate the patient 30(85\%), and did not check cuff pressure $35(100 \%)$ prior to suctioning. Likewise, at post suctioning $26(74 \%)$ did not auscultate chest, $27(77 \%)$ did not hyper-oxygenate the patient and 33(94\%) did not check cuff pressure. Furthermore, a large proportion of participants were observed not reassuring the patients after the procedure $33(94 \%)$ whereas $27(77 \%)$ did not disinfect their hands post-suctioning procedure. Infection control practices were observed to be high on self-protection 34(97\%), and maintenance of catheter sterility until inserted into the airway 94\% (Mwakanyanga, Masika, \& Tarimo, 2018).

Another cross sectional study conducted on male and female nurses in one of the teaching hospital of Baghdad $(n=50)$ to assess the endotracheal suctioning knowledge and practices, according to concluding result of this study nurses have best practical level than knowledge level. Nurse's lack of knowledge regarding complications, adverse effects and contraindications complicates patient status even more. Nurse's knowledge pertaining normal saline instillation and its effect was also assessed. revealed that only $14 \%$ of nurses said that saline instillation during suction procedure it's not recommended, $42 \%$ of nurses think that tachycardia, dyspnea, ventilator associated pneumonia are the result of instilling saline during suction procedure this can only mean that the nurses are not updated to current practice guidelines regarding saline instillation. The study also assessed the practical level of ICU nurses, result showed that $66 \%$ most of them gather necessary equipment for suctioning, $74 \%$ over half of nurses monitor and check function of devise before suctioning, $80 \%$ of all nurses check vital signs, half of nurses $50 \%$ only monitor oxygen saturation, $6 \%$ of all nurses only auscultate breath sounds for patients and over of half $82 \%$ of nurses don't identifies indications for suctioning to patient. This result may be supported with other researcher result showed that all nurses $100 \%$ check functioning of suctioning apparatus, monitor heart rate and record blood pressure but none of them $100 \%$ auscultate breath sounds which indicate that they don't assess the patient (Majeed, 2017).

The professional nurse's ethical duty is to proceed endotracheal suction with recommended guidelines to 
prevent hazards and promote recovery. Studies show that the most frequent complication of endotracheal suction is hypoxia. To avoid complications, standard endotracheal suction is recommended in the literature.

Significance: Insufficient management and suction of endotracheal suction can cause many complications, which can result in increased patient's hospital stay and in some cases fatalities. Nurses should therefore practice following the standard protocol to provide proper care and suctioning of endotracheal tube, as nurses are critical in performing ETT care and ETT suctioning. In Egypt, a study by Omira et al showed that there is a serious shortage of nurse endotracheal suctioning methods. Therefore, the aim of this research is to evaluate the performance of the nurse's endotracheal suctioning in relation to current recommendations.

Need of the study: With the increasing demand of quality intensive care, nurses need research because it helps them to advance their professional knowledge and skills. ETT suctioning is an essential feature of effective airway management. Nurses need to understand, evaluate and use research in their careers Therefore, it is important that nurses are aware of indications, contraindication, side effects and are able to follow current research and evidencebased approaches for swift recovery of ICU patients.. This study will help to enhance the nurses' practices and skills.

The following is a summary of various observational studies conducted in different countries in relation to the nurse's knowledge and practice of ETT suctioning.

\section{Literature Review}

2.1. Indication of suction: The suction procedure deals with the complexities of reviewing available literature about endotracheal suctioning and providing evidence-based recommendations for adult elastic care patients. Important commendations are made only when needed, catheter size should be half the lumen of ETT tube, and use vacuum pressure at lowest rate during suction, not to insert the catheter more deeply, not suctioning for more than 15 seconds, suctioning uninterrupted rather than intermittently. Avoid shaking, doing it gently because hypersensitivity lead to hypertension. As usual, always using either the closed system or open system, using the aseptic technique, the result shows that the nurses do not follow the usual suction nurses (Javadi et al., 2017).

2.2. Assessment: In order to eliminate the suction condition and its utility, the patient needs to be systematically evaluated. This means reviewing and examining the patient's vital signs, including chest auscultation prior to and after suction. According to MARS, study nurses do not usually review a patient's chest before and after suction (Maraş, Güler, Eşer, Köse, \& Nursing, 2017).

2.3. Patient preparation: ETT Suctioning is considering an upsetting and hostile experience for patients with mechanical ventilation, triggering anxiety, pain and discomfort. Thus, assurance and clarity must be given before the procedure and after it. Studies show that most of the time nurses do not bother patients to explain the procedure (Chegondi et al., 2018).

2.4. Hand washing: Meanwhile, $62 \%$ of participants in the Career and Andrews study found that they do not wash their hands before suction, an assumption that nurses think wearing gloves is an alternative to handwashing, in the care of the patient, a world-class precaution. Consider, besides wearing gloves, washing hands before and after contacting the patient (Morrow \& Argent, 2008).

2.5. Pre-oxygenation: Suction can often cause hypoxia, and alter cardiac rhythm, low blood pressure and unfluctuating cardiac arrest. To avoid these kind of problems, it is suggested to pre-oxygenate first. Oxygen must be lowered after finishing the suction to inhibit oxygen toxicity, nurses are well aware of this (Maraş et al., 2017).

2.6. Infection Control: Suction is an intrusive technique related with an augmented hazard of contamination. So, it is commended to wash hands before the suction, wear gown, gloves \& glasses during the suction, a recent research argued that nurses need to wash hands frequently before suction (Dexter \& Scott, 2019).

2.7. Selection of catheter: The size of the catheter used for suction must not be more than $1 / 2$ of the size of the ETT lumen. Studies revealed that larger size catheter cause tissue injury and trauma, while smaller catheters may not be effective in clearing ETT from secretion. The simplest way to calculate the catheter size is maximum size suction catheter which is half the size of the ETT, most of the researches have shown that nurses choosing the right catheter size because they know and were very good at this principle (Javadi et al., 2017).

2.8. Negative pressure: theoretically vacuum pressure for suction would be 80 and $150 \mathrm{~mm} \mathrm{Hg}$ or $10-20 \mathrm{kPa}$. Since high pressure has been revealed to cause tissue injury, trauma, hypoxia and athleticism. The catheter should be used only during withdrawing to prevent tracheal mucosa from negative pressure and the negative pressure would be applied periodically (Sohn et al., 2018).

2.9. Suction duration: The suggested procedure time for suctioning is 10 to 15 seconds, as length of time may lead to hypoxia and pain, according to Cardoso nurses who are well-known in that time frame and suctioning, perform the task well(Cardoso, Kusahara, Guinsburg, \& Pedreira, 2017).

2.10. Number of suction passes: catheter inserting numbers can play a significant role in the complication events, therefore, more than three time insertion should be prohibited during any single suctioning session (Atrous \& Hassan, 2017).

2.11. Post suctioning oxygen therapy: To minimize the danger of hypoxia, oxygenate the patient well by ambo- 
bagging or reconnect the ventilator as soon as completing the suction, studies show that ICU nurses adhere to this behavior well (Cardoso et al., 2017).

2.12. Normal saline instillation: there is a myth that saline administration during ETT suction directly increase the volume of secretion and facilitate removal of secretions, due to lack of evidence of the direct benefit of saline instillation and the evidence that saline solution increase the likelihood of adverse effects, the American Association for Respiratory Care (AARC) suggested that Saline instillation avoided during endotracheal suctioning (Owen et al., 2016).

2.13. Auscultation: An observational study conducted in Iran among critical care nurses by the Somai Higi Ferries in Iran shows that $10 \%$ of participants in this study did not auscultate patient's chest before suctioning and approximately $3232 \%$ of the nurses developed the patient's position in semi-follower position, which is not only convenient position for patient but also for nurses to perform suctioning in comfortable posture (Haghighat, Yazdannik, \& research, 2015).

2.14. Monitoring: According to the AARC guidelines of the ETT suction, nurses during and after suction should hear respiratory sound, SPo2, skin color, heart rate, breathing pattern, blood pressure, saliva (color,Volume, consistency, \& odor) and ventilator parameters. In a research conducted in ICU $(\mathrm{n}=72)$ nurses at a teaching hospital in western Turkey, through a 31-item structured checklist on ETT suctioning to determine the level of practice of nurses, their results indicate that the critical parameters of the patient during and after the practice of nurse supervision were appropriate (Maraş et al., 2017).

\section{Methodology}

3.1. Setting

A study carried out in one of the tertiary care hospital, Lahore,Pakistan

3.2. Research design

An observational cross sectional study design was used in this research.

3.3. Population

Target population of the study was Pediatric ICU nurses

3.4. Sampling

Convenient sampling technique was used.

Sample Size:

$\mathrm{N}=130$ (CICU\#15, CSICU\#40, MICU\#46, SICU\#29)

$\mathrm{n}=98$

Sample size calculated by Slovin's formula

\subsection{Tools for data collection:}

The tool has two parts: Part 1: The social demographic feature, which consists of 5 variables.

Part 2: Contains two tools: The first tool was a questionnaire for assessing knowledge about endotracheal suction, which referred to nurses' level of knowledge about endotracheal suction as having two options for answering. Using the item's correct response measured (where $1=$ false answer, $2=$ correct answer), the second tool used was a checklist to evaluate nursing performance regarding the endotracheal suctioning procedure by observation method. The options that are referred to are used to perform directly (where $1=$ not done, $2=$ done).

3.6. Data analysis: The data were analyzed via the SSPS package, which includes the descriptive statistics approach (frequency, percentage, and score mean). The level of knowledge was kept in three levels. (1-1.34) the score is poor knowledge, (1.34-1.67) fair score knowledge, and (1.67-2) good score knowledge, and practice level is rated in three levels. (1-1.34) are poor practices, (1.34-1.67) are fair practice, and (1.67-2) are good practice. Instrument Accuracy and Reliability: The content of the questionnaire was verified by a panel of experts (12). The questionnaire reliability was determined by the Pilot Study test re-test $(r=0.80)$ (Majeed, 2017).

\subsection{Study Timeline}

Study was done from January 2020 to March 2020.

\section{Ethical consideration}

The rules and regulations set by the ethical committee of Lahore school of nursing followed while conducting the research and the rights of the research participants respected.

- Oral informed consent taken from all the participants.

- All information and data collection kept confidential.

- Participants remain anonymous throughout the study.

- The subjects informed that there are no disadvantages or risk on the procedure of the study.

- They informed that they were free to withdraw at any time during the process of the study.

- Data was kept in under key and lock while keeping keys in hand. In a laptop it kept under password.

\section{Results}

This section represents the distribution of the participant by demographic characteristics of the ICU Nurses in the 
form of frequency and percentage.

\section{DEMOGRAPHIC DATA}

\begin{tabular}{lccc}
\hline Variables & Options & frequency & Percentage \\
\hline Age of respondent & $20-24$ Years & 21 & 21.4 \\
& $25-29$ Years & 53 & 54.1 \\
& $30-34$ Years & 19 & 19.4 \\
& $>35$ year & 5 & 5.1 \\
Professional & Diploma nursing & 79 & 80.6 \\
Education & generic BScN & 19 & 19.4 \\
& Diploma in ICU & 39 & 39.8 \\
Specialty & Diploma in CCU & 24 & 24.5 \\
& None & 35 & 35.7 \\
& CICU & & 10.2 \\
Working Unit & CSICU & 10 & 32.7 \\
& MICU & 32 & 38.8 \\
& SICU & 38 & 18.4 \\
Working Experience & <YYear & 18 & 15.3 \\
& $3-5 y e a r$ & 15 & 51.0 \\
& $>5 y e a r$ & 50 & 33.7 \\
\hline
\end{tabular}

Throughout the data analysis of the present study, the findings show that the majority of the nurses $75 \%$ were of the age group (20-29), most of them had a diploma in nursing (80\%). The intensive care unit nurses had less than three years of employment was $15 \%$, the majority (51) were employed (3-5) years in nursing (Table 1).

Table 2:

Table 2 represents the ETT suctioning knowledge of ICU nurses in the form of frequency and percentage.

\section{Table\#02}

RESPONDENT KNOWLEDGE TEST ABOUT ENDOTRACHEAL SUCTIONING

\begin{tabular}{|c|c|c|c|c|}
\hline Questions & Options & Frequency & Percentage & Mean \\
\hline \multirow{2}{*}{$\begin{array}{l}\text { 1) How frequently should the endotracheal /tracheal } \\
\text { suctioning be done? }\end{array}$} & $1=$ Incorrect & 4 & 4.1 & \multirow[t]{2}{*}{1.96} \\
\hline & $2=$ Correct & 94 & 95.9 & \\
\hline \multirow[t]{2}{*}{ 2) Which is the best method of suctioning? } & $1=$ Incorrect & 67 & 68.4 & \multirow[t]{2}{*}{1.32} \\
\hline & $2=$ Correct & 31 & 31.6 & \\
\hline \multirow{3}{*}{$\begin{array}{l}\text { 3) While giving nasotracheal suctioning to an adult patient, } \\
\text { suction catheter } \\
\text { Should it be inserted up to? }\end{array}$} & $1=$ Incorrect & 64 & 65.3 & \multirow[t]{3}{*}{1.35} \\
\hline & $2=$ Correct & 34 & 34.7 & \\
\hline & & & & \\
\hline \multirow{2}{*}{$\begin{array}{l}\text { 4) Which of the following is true regarding endotracheal } \\
\text { suctioning? }\end{array}$} & $1=$ Incorrect & 13 & 13.3 & \multirow[t]{2}{*}{1.87} \\
\hline & $2=$ Correct & 85 & 86.7 & \\
\hline \multirow{2}{*}{$\begin{array}{l}\text { 5) The maximum time limit for an endotracheal suctioning } \\
\text { is? }\end{array}$} & $1=$ Incorrect & 9 & 9.2 & \multirow[t]{2}{*}{1.91} \\
\hline & $2=$ Correct & 89 & 90.8 & \\
\hline \multirow{4}{*}{$\begin{array}{l}\text { 6) Which is the most appropriate position for giving } \\
\text { endotracheal suctioning? } \\
\text { 7) Successful suctioning is confirmed by which method? }\end{array}$} & $1=$ Incorrect & 9 & 9.2 & \multirow[t]{2}{*}{1.91} \\
\hline & $2=$ Correct & 89 & 90.8 & \\
\hline & $1=$ Incorrect & 61 & 62.2 & \multirow[t]{2}{*}{1.38} \\
\hline & $2=$ Correct & 37 & 37.8 & \\
\hline \multirow{4}{*}{$\begin{array}{l}\text { 8) Which of the nerve is stimulated during endotracheal } \\
\text { suctioning? } \\
\text { 9) Which will be the possible complication of suctioning } \\
\text { due to irritation of } \\
\text { Carina? }\end{array}$} & $1=$ Incorrect & 44 & 44.9 & \multirow[t]{2}{*}{1.55} \\
\hline & $2=$ Correct & 54 & 55.1 & \\
\hline & $1=$ Incorrect & 23 & 23.5 & \multirow[t]{2}{*}{1.77} \\
\hline & $2=$ Correct & 75 & 76.5 & \\
\hline \multirow{2}{*}{$\begin{array}{l}\text { 10) what is the recommended suction pressure for } \\
\text { endotracheal suctioning in }\end{array}$} & $1=\operatorname{Inc}$ & 7 & 7.1 & \multirow{2}{*}{1.93} \\
\hline & $2=$ Correct & 91 & 92.9 & \\
\hline
\end{tabular}




\begin{tabular}{|c|c|c|c|c|}
\hline Questions & Options & Frequency & Percentage & Mean \\
\hline \multicolumn{5}{|l|}{ Adults? } \\
\hline \multirow{2}{*}{$\begin{array}{l}\text { 11) How frequently should the ET suction catheter be } \\
\text { changed? }\end{array}$} & $1=$ Incorrect & 6 & 6.1 & \multirow[t]{2}{*}{1.94} \\
\hline & $2=$ Correct & 92 & 93.9 & \\
\hline \multirow{2}{*}{$\begin{array}{l}\text { 12) Which one of the following complication can arise due } \\
\text { to the absence of Hyperventilation before giving } \\
\text { suctioning? }\end{array}$} & $1=$ Incorrect & 8 & 8.2 & \multirow[t]{2}{*}{1.92} \\
\hline & $2=$ Correct & 90 & 91.8 & \\
\hline \multirow{2}{*}{$\begin{array}{l}\text { 13) Sodium bicarbonate should not be instilled through the } \\
\text { ET tube why? }\end{array}$} & $1=$ Incorrect & 19 & 19.4 & \multirow[t]{2}{*}{1.81} \\
\hline & $2=$ Correct & 79 & 80.6 & \\
\hline \multirow{4}{*}{$\begin{array}{l}\text { 14) You are being asked to do an endotracheal suctioning } \\
\text { for a patient with ET Tube size } 8 \mathrm{~mm} \text {. the appropriate size } \\
\text { of suction catheter you will choose for this Patient is? } \\
\text { 15) Prevention of nosocomial infections? }\end{array}$} & $1=$ Incorrect & 60 & 61.2 & \multirow[t]{2}{*}{1.39} \\
\hline & $2=$ Correct & 38 & 38.8 & \\
\hline & $1=$ Incorrect & 10 & 10.2 & 1.90 \\
\hline & $2=$ Correct & 88 & 89.8 & \\
\hline \multirow[t]{2}{*}{ 16) Effect of Preoxygenation in ETS } & $1=$ Incorrect & 7 & 7.1 & \multirow{2}{*}{1.93} \\
\hline & $2=$ Correct & 91 & 92.9 & \\
\hline \multirow[t]{2}{*}{ 17) Contraindications for ETS } & $1=$ Incorrect & 56 & 57.1 & \multirow[t]{2}{*}{1.43} \\
\hline & $2=$ Correct & 42 & 42.9 & \\
\hline \multirow[t]{2}{*}{ 18) Normal Saline instillation during ETS } & $1=$ Incorrect & 9 & 9.2 & \multirow[t]{2}{*}{1.91} \\
\hline & $2=$ Correct & 89 & 90.8 & \\
\hline \multirow[t]{2}{*}{ 19) The reason behind the discontinuation of the procedure } & $1=$ Incorrect & 8 & 8.2 & \multirow[t]{2}{*}{1.92} \\
\hline & $2=$ Correct & 90 & 91.8 & \\
\hline \multirow[t]{2}{*}{ 20) Effect of increased ETS frequency } & $1=$ Incorrect & 71 & 72.4 & \multirow[t]{2}{*}{1.28} \\
\hline & $2=$ Correct & 27 & 27.6 & \\
\hline
\end{tabular}

\subsection{Knowledge}

One of the objectives of the study, to evaluate the knowledge of the intensive care unit nurses about endotracheal tube suctioning for children patients (Table 2) In the present study, the average of nurses' scores in knowledge and performance show that the level of knowledge Was calculated in three levels; (1-1.34) poor knowledge of the score, (1.34-1.67) fair score knowledge, and (1.67-2) good score knowledge, and practice level. Rated in three levels. (1-1.34) are poor practices, (1.34-1.67) are fair exercises, and (1.67-2) are good practice, this study revealed that $96 \%$ of nurses know well how frequently ETT suction is necessary for the patient. 32\% said that closed procedure for endotracheal tube suctioning is best, whereas round about $68 \%$ of ICU nurses do not know which is the best method of suctioning as there were practicing open suctioning in their set up rather than the close system, $50 \%$ of nurses respond that a nasotracheal suction catheter is inserted from 16 to $20 \mathrm{~cm}, 87 \%$ of nurses viewed that endotracheal tube suction should be performed during withdrawal. $90 \%$ of ICU nurses know about the maximum time limit for an ETT suctioning, 90\% of ICU nurses know well which the best position for giving ETT suctioning is.

This result does not agree with that of the other researcher who reported that $66.6 \%$ of ICU nurses think that endotracheal/tracheal suctioning be done when needed, 100\% majority of them asked that closed method the best for ETS, $43.33 \%$ of nurses said about nasotracheal suctioning to an adult patient suction catheter should be inserted up to $16-20 \mathrm{~cm}$, majority of them asked that endotracheal suctioning tube removed when withdrawal catheter, 93.33\% maximum time limit for an endotracheal suctioning was 10-15 second, $63.33 \%$ semi fowlers position most appropriate position for giving endotracheal suctioning, 96.66\% ET suction catheter be changed after suctioning(Majeed, 2017).

Another objective was the nurse's knowledge concerning endotracheal suctioning complication during suctioning, revealed that $62 \%$ of ICU nurses do not know which method is used to confirm that suction is successful. Only $38 \%$ of them know it correctly. $55 \%$ of ICU nurses know which of the nerve is stimulated during ETT suctioning, round about $76 \% \%$ of ICU nurses know which will be the possible complication of suctioning due to irritation of Carina, $92 \%$ of ICU nurses know it well that what is the recommended suction pressure for ETT suction in adult as well as in children?

The results of the study agree with a study by other researchers who stated that $45.2 \%$ of them use $80-120$ $\mathrm{mm} \mathrm{Hg}$ pressure. It revealed that more than half of the nurses use a size that is less than the inner diameter of the tracheal tube, the correct tube size reduces the patient's discomfort and tracheal mucosa. Total knowledge was assessed using the Grading Scale for Knowledge. The score at one of the teaching hospitals demonstrates the total 
level of knowledge resources and as it has been observed that the majority of ICU nurses (1.49) have adequate knowledge of the method of ETT suctioning (Majeed, 2017).

In this study $94 \%$ of ICU nurses know how frequently the ETT suction catheter should be changed, $92 \%$ of ICU nurses know correctly which one of the following complications can arise due to the absence of hyperventilation before giving suctioning, rest of them do not know about that. $80 \%$ of ICU nurses know how sodium bicarbonate instillation should harm patient lung tissue during ETT suctioning, while $20 \%$ do not aware of the adverse effect of its usage during ETT suction.

The result is along the same line with another researcher who reported that $73.33 \%$ of them indicated that the vagus nerve is stimulated during endotracheal suction, with $80 \%$ of nurses saying that the cause of the irritation of the carina. $66.6 \%$ of nurses answer it correct that possible complications of suction with sodium bicarbonate is lung tissue-damaging(Owen et al., 2016).

About $62 \%$ of ICU nurses do not know about the exact size of the suction catheter for the tube size $8 \mathrm{~mm}$, while 38 nurses answer it correctly. $90 \%$ of ICU nurses know how to prevent a patient from nosocomial infection while frequently suctioning, $93 \%$ of ICU nurses know correctly how preoxygenation effects during ETT suction. $57 \%$ of ICU nurses do not know about the contraindication of ETT suctioning. The lack of nurse information regarding complications, adverse effects and contraindication further complicate the patient's condition. Nurse's knowledge of normal saline instillation and its effect was also assessed which revealed that $91 \%$ of ICU nurses know about the usage of Normal saline instillation during ETT suctioning, while the other 9\% do not know either normal saline usage is recommended or not. $92 \%$ of ICU nurses know the reason behind the discontinuation of the procedure, while the rest of them unaware of this parameter, the knowledge about the effect of increased frequency of suctioning was also assessed. The result showed that only $28 \%$ of nurses said that it causes atelectasis. This result reflects the nurse's lack of knowledge of suctioning frequency. Suctioning the patient too much would damage the lung mucosa.

These results were similar to those results obtained by another researcher to determine the knowledge and practice of nurses before and after training and the development of a protocol for open and closed system suctioning methods in patients with ETTs which had shown a significant increase in the post-implementation knowledge and practice score. This finding is the following result obtained by other researchers who stated the knowledge of professionals was qualified as fair $(73.2 \%$ correct), but worryingly it was considered poor (Majeed, 2017).

Table 3:

Table 3 represents the data regarding ETT suctioning practices of ICU nurses in the form of frequency and percentage.

TABLE\#03

PERFORMANCE EVALUATION

\begin{tabular}{|c|c|c|c|c|}
\hline Questions & Options & Frequency & Percentage & Mean \\
\hline \multirow[t]{2}{*}{ 1) Assemble equipment } & $1=$ Not done & 0 & 0 & 2.0 \\
\hline & $2=$ Done & 98 & 100 & \\
\hline \multirow[t]{2}{*}{ 2) Check function of suction apparatus } & $1=$ Not done & 0 & 0 & 2.0 \\
\hline & $2=$ Done & 98 & 100 & \\
\hline \multirow[t]{2}{*}{ 3) Monitor vital signs } & $1=$ Not done & 3 & 3.1 & 1.97 \\
\hline & $2=$ Done & 95 & 96.9 & \\
\hline \multirow[t]{2}{*}{ 4) Monitor oxygen saturation } & $1=$ Not done & 5 & 5.1 & 1.95 \\
\hline & $2=$ Done & 93 & 94.9 & \\
\hline \multirow[t]{2}{*}{ 5) Auscultate breath sounds. } & $1=$ Not done & 18 & 18.4 & 1.18 \\
\hline & $2=$ Done & 80 & 81.6 & \\
\hline \multirow[t]{2}{*}{ 6) Explain the procedure to the patient } & $1=$ Not done & 5 & 5.1 & 1.95 \\
\hline & $2=$ Done & 93 & 94.9 & \\
\hline \multirow[t]{2}{*}{ 7) Identifies indications for suctioning. } & $1=$ Not done & 0 & 0 & 2.00 \\
\hline & 2=Done & 98 & 100 & \\
\hline \multirow{2}{*}{$\begin{array}{l}\text { 8) Places the patient in the supine position with the } \\
\text { head slightly extended. }\end{array}$} & $1=$ Not done & 0 & 0 & 2.00 \\
\hline & $2=$ Done & 98 & 100 & \\
\hline \multirow[t]{2}{*}{ 9) Prepares ambo bag and oxygen supply } & $1=$ Not done & 0 & 0 & 2.00 \\
\hline & $2=$ Done & 98 & 100 & \\
\hline \multirow[t]{2}{*}{ 10) Checks suction device with connecting tubing } & $1=$ Not done & 0 & 0 & 2.00 \\
\hline & $2=$ Done & 98 & 100 & \\
\hline \multirow[t]{2}{*}{ 11) Attaches sterile suction catheter. } & $1=$ Not done & 0 & 0 & 2.00 \\
\hline & $2=$ Done & 98 & 100 & \\
\hline \multirow{2}{*}{$\begin{array}{l}\text { 12) Pour normal saline into the bowl for cleaning } \\
\text { tubing }\end{array}$} & $1=$ Not done & 0 & 0 & 2.00 \\
\hline & $2=$ Done & 98 & 100.0 & \\
\hline
\end{tabular}




\begin{tabular}{|c|c|c|c|c|}
\hline Questions & Options & Frequency & Percentage & Mean \\
\hline \multirow[t]{2}{*}{ 13) Wash hands } & $1=$ Not done & 37 & 37.8 & 1.62 \\
\hline & $2=$ Done & 61 & 62.2 & \\
\hline \multirow[t]{2}{*}{ 14) Puts on mask } & $1=$ Not done & 44 & 44.9 & 1.55 \\
\hline & $2=$ Done & 54 & 55.1 & \\
\hline \multirow[t]{2}{*}{ 15) Place the sterile gloves on the towel/bed table } & $1=$ Not done & 0 & 0 & 2.00 \\
\hline & $2=$ Done & 98 & 100.0 & \\
\hline \multirow[t]{2}{*}{ 16) Put on the sterile gloves } & $1=$ Not done & 0 & 0 & 2.00 \\
\hline & $2=$ Done & 98 & 100.0 & \\
\hline \multirow[t]{2}{*}{ 17) Place the sterile towel on the patient's chest } & $1=$ Not done & 0 & 0 & 2.00 \\
\hline & $2=$ Done & 98 & 100.0 & \\
\hline \multirow[t]{2}{*}{ 18) Hyper oxygenate the patient before suctioning } & $1=$ Not done & 0 & 0 & 2.00 \\
\hline & $2=$ Done & 98 & 100.0 & \\
\hline \multirow{2}{*}{ 19) Don't apply suction while inserting the catheter } & $1=$ Not done & 0 & 100.0 & 2.00 \\
\hline & $2=$ Done & 98 & & \\
\hline \multirow[t]{2}{*}{ 20) Removes catheter in a rotating movement } & $1=$ Not done & 0 & 100.0 & 2.00 \\
\hline & $2=$ Done & 98 & & \\
\hline \multirow[t]{2}{*}{ 21) Limits suction time to $10-15$ seconds } & $1=$ Not done & 0 & 100.0 & 2.00 \\
\hline & $2=$ Done & 98 & & \\
\hline \multirow{2}{*}{$\begin{array}{l}\text { 22) Discontinue if the heart rate is below or above } \\
\text { normal }\end{array}$} & $1=$ Not done & 0 & 100.0 & 2.00 \\
\hline & $2=$ Done & 98 & & \\
\hline \multirow[t]{2}{*}{ 23) Resumes oxygen delivery system } & $1=$ Not done & 0 & 100.0 & 2.00 \\
\hline & 2=Done & 98 & & \\
\hline \multirow{2}{*}{$\begin{array}{l}\text { 24) Rinse catheter and suction tube with normal saline } \\
\text { until clear }\end{array}$} & $1=$ Not done & 0 & 0 & 2.00 \\
\hline & $2=$ Done & 98 & 100.0 & \\
\hline 25) After & $1=$ Not done & 0 & o & 2.00 \\
\hline ventilator $100 \% \mathrm{O} 2$ & $2=$ Done & 98 & 100.0 & \\
\hline \multirow[t]{2}{*}{ 26) Reassess the patient's respiratory status } & $1=$ Not done & 0 & 0 & 2.00 \\
\hline & 2=Done & 98 & 100.0 & \\
\hline \multirow[t]{2}{*}{ 27) Don't perform more than 4 suction per suctioning } & $1=$ Not done & 1 & 1.0 & 1.99 \\
\hline & $2=$ Done & 97 & 99.0 & \\
\hline \multirow[t]{2}{*}{ 28) Discards equipment after suction } & $1=$ Not done & 0 & 0 & 2.00 \\
\hline & $2=$ Done & 98 & 100.0 & \\
\hline \multirow[t]{2}{*}{ 29) Perform hand wash } & $1=$ Not done & 13 & 13.3 & 1.87 \\
\hline & $2=$ Done & 85 & 86.7 & \\
\hline \multirow[t]{2}{*}{ 30) Monitor any changes in the vital signs } & $1=$ Not done & 0 & 0 & 2.00 \\
\hline & $2=$ Done & 98 & 100.0 & \\
\hline \multirow[t]{2}{*}{ 31) Document of suction procedure } & $1=$ Not done & 16 & 16.3 & 1.84 \\
\hline & $2=$ Done & 82 & 83.7 & \\
\hline
\end{tabular}

\subsection{Practices}

The study also assessed the practical level of ICU nurses (Table 3) The total practice level was analyzed by practice grading scale level of practice was ranked into three levels; (1-1.34) for poor practice, (1.34-1.67) for fair practice, and more than (1.67-2) for good practice

The result showed that all of them gather necessary equipment for suctioning, $100 \%$ of ICU nurses monitor and check the function of a device before suctioning, $97 \%$ of all nurses check vital signs, $95 \%$ monitor oxygen saturation, $19 \%$ of all nurses only auscultate breath sounds for patients and $100 \%$ of nurses identify indications for suctioning to patient. This result may be supported by other researcher's results showed that all nurses $100 \%$ check functioning of suctioning apparatus, monitor heart rate and record blood pressure but none of them $100 \%$ auscultate breath sounds which indicate that they don't assess the patient. Nurses practices regarding infection- control prevention data showed, the majority of nurses $63 \%$ perform hand hygiene before suctioning, $100 \%$ of nurses wear sterile gloves, also the majority of nurses put face mask, and most of them connect sterile suction catheter this finding demonstrates the majority of nurses using precaution transmission through performing procedure to prevent infection.

This result agrees with that of the other researcher who reported that Concerning the use of personal protective equipment (PPE), similarly to what is found in the literature high adherence to the use of gloves was ascertained $(92 \%)$ as was regular use of the mask and apron (72\% and 60\%), although there was no adherence to the use of 
eye protection $(0 \%)$. Studies have shown that the nurses themselves, despite recognizing the importance of the use of PPE, do not use it appropriately when undertaking the ETS procedure(Mwakanyanga, Masika, \& Tarimo, 2018).

Observation of Infection- control measure: $84 \%$ Place the sterile gloves on the towel/bed table during procedure, $84 \%$ of nurses don't place a towel over the chest of the patient, the majority of the $80 \%$ destroy equipment and $84 \%$ of nurses perform handwashing after suctioning. Regarding the measures recommended to be taken immediately before the suctioning, most of them $74 \%$ give hyper oxygenation to the patient before suctioning, majority of the $82 \%$ of them Prepares ambo bag and oxygen supply, majority of the $82 \%$ used normal saline or distilled water to rinse suctioning tube until clear, $56 \%$ of nurses don't aspirate while insert catheter, only $36 \%$ of nurses removes catheter in a rotating movement. The majority of ICU nurses resumes oxygen delivery system, $100 \%$ of nurses stop suctioning immediately if the heart rate above or low normal level, and $100 \%$ give hyper oxygenation directly after suctioning, all of them monitor any change hemodynamic status during suction, only $98 \% \%$ of nurses don't perform more than four suction per suctioning and $100 \%$ of nurse's limits suction time to $10-15$ seconds.

The findings agree with another researcher who stated that the patient should be reconnected to oxygen within 10 seconds post the suctioning majority of them $89.2 \%$, Post suctioning hyper oxygenation most of them $62.5 \%$ patient reassured respiratory status $55.3 \%, 75.05$ number of suction passes $\leq 2$, and $72.5 \%$ duration of suction applied to the airway ( $<15$ seconds). Nurse's practice related nursing documentation for endotracheal tube suctioning procedure the result demonstrates most of them $70 \%$ of nurses document suctioning procedure. The finding is disagreeing with another researcher who stated all of the nurse's intensive care unit doesn't document suctioning procedure (Majeed. 2017).

\section{Limitation}

Limitation of this study was short sample size and less time period which we cannot generalize this study on whole population.

\section{Conclusion}

Even though this survey is restricted according to the number of ICU nurses who respond to these questionnaires, it gives an overview of the ICU nurse's knowledge and performance about ETT suctioning procedure. This study demonstrates that intensive care nurses' performance regarding endotracheal suctioning is good enough despite fair knowledge. With concerning to these finding there is a need for educational courses, especially theoretical education and motivational session to follow the standard protocol for ETT suction.

\section{Recommendation}

Educational program/session for ICU nurses to enhance their knowledge and practices about ETT suction, there is also a need to place practice guidelines and periodic teaching and training sessions held in all intensive care units. Urge this type of research in such a setting for evaluating self-deficiencies and for improvement too.

\section{References}

Atrous, A. E.-H., \& Hassan, M. J. E. J. o. H. C. (2017). Evaluation the Gap between Knowledge and Practice in Open System Endo-Tracheal Suctioning among Critical Care Nurses. 8(3), 248-260.

Cardoso, J. M., Kusahara, D. M., Guinsburg, R., \& Pedreira, M. L. J. N. i. c. c. (2017). Randomized crossover trial of endotracheal tube suctioning systems use in newborns. 22(5), 276-283.

Chegondi, M., Francis, T., Lin, W.-C., Naqvi, S., Raszynski, A., \& Totapally, B. R. J. P. C. C. M. (2018). Effects of closed endotracheal suctioning on systemic and cerebral oxygenation and hemodynamics in children. 19(1), e23-e30.

Davies, K., Bulsara, M. K., Ramelet, A.-S., \& Monterosso, L. J. C. n. r. (2017). Audit of endotracheal tube suction in a pediatric intensive care unit. 26(1), 68-81.

Dexter, A. M., \& Scott, J. B. J. R. c. (2019). Airway Management and Ventilator-Associated Events. 64(8), 986993.

Haghighat, S., Yazdannik, A. J. I. j. o. n., \& research, m. (2015). The practice of intensive care nurses using the closed suctioning system: An observational study. 20(5), 619.

Javadi, M., Hejr, H., Zolad, M., Khalili, A., Paymard, A. J. A. o. T. M., \& Health, P. (2017). Comparing the effect of endotracheal tube suction using open method with two different size catheters 12 and 14 on discharge secretion, pain, heart rate, blood pressure, and arterial oxygen saturation of patients in the intensive care unit: A randomized clinical trial. 10(5), 1312.

Maraş, G. B., Güler, E. K., Eşer, İ., Köse, Ş. J. I., \& Nursing, C. C. (2017). Knowledge and practice of intensive care nurses for endotracheal suctioning in a teaching hospital in western Turkey. 39, 45-54.

Morrow, B. M., \& Argent, A. C. J. P. C. C. M. (2008). A comprehensive review of pediatric endotracheal suctioning: Effects, indications, and clinical practice. 9(5), 465-477. 
Majeed, H. M. J. I. J. R. M. S. (2017). Assessment of knowledge and practices of intensive care unit nurses about endotracheal suctioning for adult patients in Baghdad teaching hospitals, Iraq. 5, 4.

Mwakanyanga, E. T., Masika, G. M., \& Tarimo, E. A. J. P. o. (2018). Intensive care nurses' knowledge and practice on endotracheal suctioning of the intubated patient: A quantitative cross-sectional observational study. 13(8).

Owen, E. B., Woods, C. R., O’Flynn, J. A., Boone, M. C., Calhoun, A. W., \& Montgomery, V. L. J. C. c. n. (2016). A bedside decision tree for use of saline with endotracheal tube suctioning in children. 36(1), e1-e10.

Sohn, H., Baik, J., Hwang, J., Kim, S., Han, S. H., \& Kim, J. J. B. a. (2018). Devising negative pressure within intercuff space reduces microaspiration. 18(1), 1-7 